\title{
Orthopaedic Implant Failure
}

\author{
Onuoha K M*, Omotola O E, Bulus B B, Alo M and Onuoha C E 0 \\ *Department of Geology, Nigeria \\ *Corresponding author: K M Onuoha, Department of Geology, Nigeria
}

\begin{abstract}
Background: Implant failure refers to the inability of any medical implant to meet the claims of its manufacturer or the health care provider who installs it. Some implants tend to fail more than others depending on location, type of implant and age of patient. Other pathologies such as infection, trauma and pathologic fractures are additional risk factors.

Objectives: To determine the pattern of orthopaedic implant failure and possible risk factors in a Nigerian tertiary hospital.

Methodology: A retrospective hospital-based study carried out over 10 years (January 2007 to December 2017) in which case notes of patients who had implant surgeries done were reviewed to determine those who had implant failure, the possible cause, treatment offered and outcome. Results were collated and subsequently analysed.

Results: Majority were females (60\%) and mean age was 48yrs +/- 2.2. Most surgeries were in the lower limbs and Infection was the strongest single risk factor identified (40\%). Revision surgery was carried out for all and majority (86.7\%) were without bone grafts. However, all yielded satisfactory outcome.

Conclusion: Implant failure occurs more in the lower limb surgeries and affects middle aged females more. Infection is a strong risk factor however there is no association between aetiology and gender. Bone grafting in revision surgery does not affect outcome. The components of implants need to be further evaluated to determine risk of failure.
\end{abstract}

\section{Introduction}

Orthopaedic implants are artificial mechanical devices that are mounted to the skeletal system of the human body for various purposes, such as supporting bone, replacing bones or joints and reattaching tendons or ligaments [1]. Implant survival is the time from the date of implant placement to the date of its failure [2]. Implants are made of different types of biomaterials like Titanium, stainless steel, polymers and composite materials. A good biomaterial should have such properties as good mechanical and biological compatibility and enhanced corrosion resistance [3]. An Implant is said to have failed when there is a need to remove the implant prematurely [4].

\section{Methodology}

A retrospective hospital-based study carried out in Wesley Guild Hospital, Ilesha, in which case notes of patients who had implant failure over a 10-year period (January 2007 to December 2017) were retrieved, data such as demography, type of implant, cause of failure and treatment offered were collated and enteredinto a profoma and subsequently analysed. Statistical analysis was done using simple frequencies and chi squared test for association.

\section{Results/Discussion}

During the study period, a total of 535 patients had open reduction and internal fixation out of which 15 patients $(2.8 \%)$ were noted to have implant failure and subsequently had their implants removed. This low incidence reflects the adequate concern given for implant surgeries preoperatively, Intraoperatively and postoperatively. The age ranged from 23years to 98 years with a mean age of 48+/- 2.2 Previous studies done showed an average age of 35 years in patients with implant failure [5]. This may be attributed to the activity found more in this age group. The time to implant failure ranged from 9days, to 16 months with a mean of $3+/-4$ months. In a study done in 2002, it was noted that most failures occur less than 2 years following the initial surgery [6]. Time to weight bearing following implant removal ranged from 1 month to 5 months with a mean of 2.7+/- 1.1 months (Figure 1). 
The Figure 1 above shows the gender distribution of patients with implant failure. It is noted that $40 \%$ of the patients were males while $60 \%$ were females.

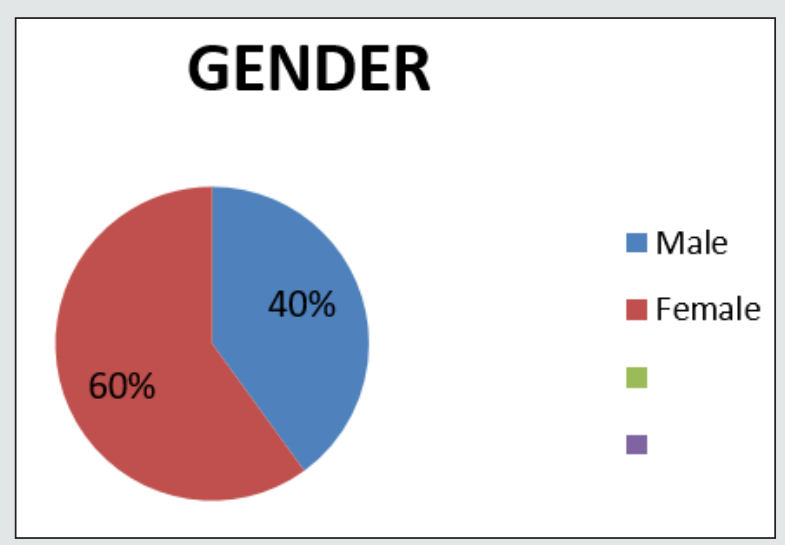

Figure 1: gender distribution of patients with implant failure.

Table 1: Nature of implant.

\begin{tabular}{|c|c|c|}
\hline & N & \% \\
\hline Intramedullary Nail & 1 & 6.7 \\
\hline Plate and Screw for Tibiofibular/Ankle Fractures & 8 & 53.3 \\
\hline Dynamic Hip Screw & 1 & 6.7 \\
\hline K-Wires for Corrective Osteotomy & 1 & 6.7 \\
\hline Malleolar Screw & 2 & 13.3 \\
\hline Condylar Blade Plate & 1 & 6.7 \\
\hline Pedicle Screws & 1 & 6.7 \\
\hline Total & 15 & 100 \\
\hline
\end{tabular}

Table 2: Causes of Failure.

\begin{tabular}{|c|c|c|}
\hline & $\mathbf{N}$ & $\mathbf{\%}$ \\
\hline Pathological fracture & 1 & 6.7 \\
\hline Infection & 6 & 40 \\
\hline Implant breakage & 3 & 20 \\
\hline Trauma & 1 & 6.7 \\
\hline Implant exposure & 1 & 6.7 \\
\hline Total & 12 & 80 \\
\hline Idiopathic & 3 & 20 \\
\hline Total & 15 & 100 \\
\hline
\end{tabular}

This finding is similar to a study done in 2009 where it was noted that females are at higher risk of early implant failure [7]. This could be due to their higher body mass index thus putting more stress on the implants (Tables 1-3). The frequency table above shows the nature of implants that failed over the study period and the causes of failure (Figure 2). It is noted that most of the implants were in the lower limbs, this could be attributed to the lower limb bearing the body weight and hence the implant sharing the weight. It is noted that plates and screws had the highest incidence, (53.3\%). This could be explained by plates and screws being load sharing devices as against nails which are load bearing devices. There was an equal incidence for spine implants, locked intramedullary nails, Dynamic hip screw and corrective osteotomy implants (6.7\%). There is however paucity of data regarding nature of implants which commonly fail rather it is more of the contents of the implant [8].

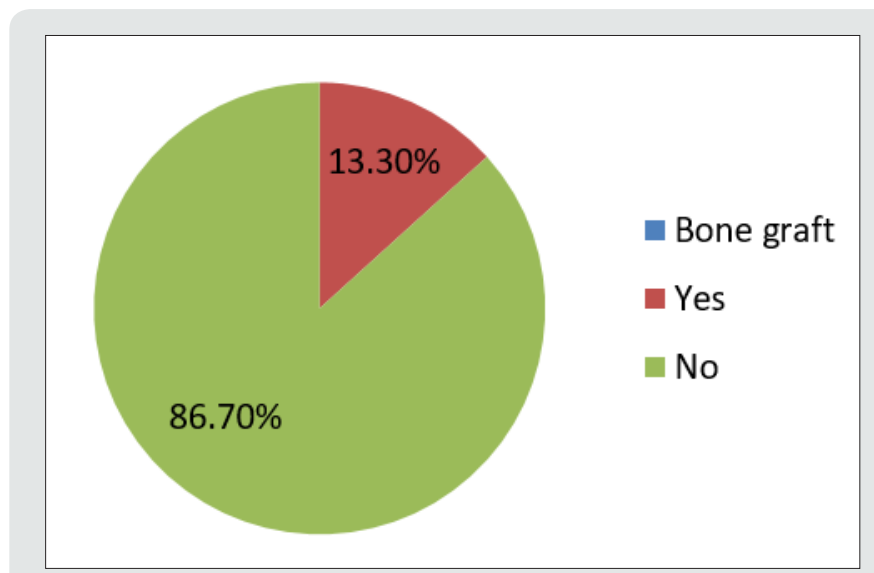

Figure 2: Bonegraft in revision surgery.

Table 3: Association between aetiology and gender.

\begin{tabular}{|c|c|c|c|c|c|}
\hline & Male & Female & Total & X2 & P value \\
\hline & $\mathbf{n}(\%)$ & $\mathbf{n}(\%)$ & $\mathbf{n}(\%)$ & & \\
\hline $\begin{array}{c}\text { Pathological } \\
\text { fracture }\end{array}$ & $0(0.0)$ & $1(8.3)$ & $1(8.3)$ & & \\
\hline Infection & $2(16.7)$ & $4(33.3)$ & $6(50.0)$ & & \\
\hline Implant break & $2(16.7)$ & $1(8.3)$ & $3(25.0)$ & & \\
\hline Trauma & $1(8.3)$ & $0(0.0)$ & $1(8.3)$ & & \\
\hline $\begin{array}{c}\text { Implant } \\
\text { exposure }\end{array}$ & $0(0.0)$ & $1(8.3)$ & $1(8.3)$ & & \\
\hline Total & $5(41.7)$ & $7(58.3)$ & $12(100)$ & 3.771 & $>4.38$ \\
\hline
\end{tabular}

Regarding aetiology, infection was noted as the commonest cause of implant failure while in another study, smoking was noted as a strong risk factor for implant failure [9]. The use of postoperative antibiotics does not reduce the chances of implant failure [10]. Thus, proper preparation of the patient and implant selection are important. Pathologic fracture, trauma and implant exposure had equal incidence of aetiology accounting for $8.3 \%$. In a study by K.V Sudhakar, it was noted that stainless steel intramedullary nail could fail due to ductile fracture facilitated by presence of non-metallic inclusions [11]. in another study, it was noted that solubility of Titanium is a cause of implant failure [12]. On further analysis, we can inffer, that there is no association between gender and implant failure given a p value of 4.3 and $\mathrm{x} 2$ of 3.77 . It is also noted that $86.7 \%$ did not have bone grafting done however, there was satisfactory outcome in all the cases which supports studies done in literature [13]. 


\section{Conclusion}

Implant failure occurs more in the lower limb surgeries and affects middle aged females more. Infection is a strong risk factor however there is no association between aetiology and gender. Bone grafting in revision surgery does not affect outcome. The components of implants need to be further evaluated to determine risk of failure.

\section{References}

1. M Sivakumar, Dhanadurai KS, S Rajeswari, Thulasiraman V (1995) Failure in stainless steel orthopaedic implant devices: a survey. Journal of Material Science Letters 14(5): 351-354.

2. V V Woo, S K Chuang, S Daher, Muftu A (2004) Dentoalveolar reconstructive procedures as a risk factor for implant failure. Journal of Oral and Maxillofacial Surgery 62(7): 773-780.

3. M Geetha, A K Singh, R Asokamani, Gogia AK (2009) Ti based biomaterials the ultimate choice for orthopaedic implants. Progress in material science 54(3): 397-425

4. Moy Peter, Medina Diana, Vivek S (2005) Dental Implant Failure Rates and Associated Risk Factors. International Journal of Oral and Maxillofacial Implants 20(4): 569-577.

5. Lonner Jess, Hershman Stuart, Michael M (2000) Total Knee Arthroplasty in Patients 40 years of Age and Younger with Osteoarthrittis. Clinical Orthopaedics and Related research 380: 85-90.
6. Sharkey Peter, Hozack William, Rothman Richard, Shani S (2002) Why are Total Knee Arthroplasties failing Today? Clinical Orthopaedics and Related research 404: 7-13.

7. Manor Y, Oubaid S, Mardinger O, Chaushu G, Nissan J (2009) Characteristics of early and late implant failure: A retrospective study. Jounal of Oral and Maxillofacial surgery 67(12): 2649-2652.

8. G K Triantafyllidis (2007) Premature fracture of a stainless steel 316L orthopaedic plate implant by alternative episodes of fatigue and cleavage decoherence. Engineering failure analysis 14(7): 1346-1350.

9. H De Bryne, Collaert B (1994) The effect of smoking on early implant failure. clinical oral implants research 5(4): 260-264.

10. Basel Sharaf, Mahar Jandalli Rifai, Dodson TB (2011) Do Perioperative Antibiotics Decrease implant failure? Journal of Oral and Maxillofacial Surgery 69(9): 2345-2350.

11. Sudhakar KV (2005) Mettallurgical investigation of a failure in 316L stainless steel orthopaedic implant. Engineering failure analysis.;12(2):249-256.

12. Lalor PA, Revell PA, Gray AB, Wright S, Railton GT, et al. (1991) Sensitivity to Titanium. A cause of implant failure? The Bone and Joint Journal 73(1): 25-28.

13. Kai Uwe Lewandroski, Joseph Gresser, Donald Wise, Trantolo D (2000) Bioresorbable bone grafts substitutes of different osteo conductivities: A histologic evaluation of osteointegration of poly(propylene glycol-cofumaric acid) based cement implants in rats. Biomaterials 21(8): 757764.

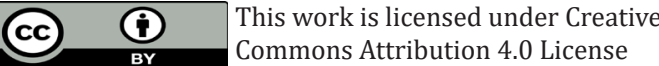

To Submit Your Article Click Here: Submit Article

$\begin{gathered}\text { Surgery \& Case Studies: Open } \\ \text { Access Journal }\end{gathered}$
Assets of Publishing with us
- Global archiving of articles
- Immediate, unrestricted online access
- Rigorous Peer Review Process
- Authors Retain Copyrights
- Unique DOI for all articles

